\title{
A framework for role allocation in education, research and leadership services in Canadian academic divisions of general surgery: a modified Delphi consensus
}

\author{
Morgann Reid, MSc \\ Alex Lee, BSc \\ Ken Leslie, MD \\ Liane S. Feldman, MDCM \\ S. Morad Hameed, MD, MPH \\ Roy Kirkpatrick, MD \\ Peter J. Lovrics, MD \\ P. Hugh MacDonald, MD \\ David Pace, MD, MBA \\ John M. Shaw, MBBCh, MMed \\ Carol J. Swallow, MD, PhD \\ Giuseppe Pagliarello, MD \\ David L. Bigam, MD, MSc \\ Geoff Porter, MD, MSc \\ Alex Mathieson, MD \\ Nathalie McFadden, MD \\ Réal Lapointe, MD \\ Tony MacLean, MD \\ Craig Kuziemsky, PhD \\ Fady Balaa, MD, MEd
}

Accepted Feb. 9, 2021

\section{Correspondence to: \\ F. Balaa \\ Division of General Surgery \\ University of Ottawa \\ The Ottawa Hospital \\ 501 Smyth Rd \\ Ottawa ON K1H 8L6 \\ fbalaa@toh.ca}

Cite as: Can J Surg 2022 February 3; 65(1). doi: 10.1503/cjs.021120
Background: Moving toward a funding standard similar to that for clinical services for roles essential to the functioning of education, research and leadership services within divisions of general surgery is necessary to strengthen divisional resilience. We aimed to identify roles and underlying tasks in these services central to sustainable functioning of Canadian academic divisions of general surgery.

Methods: Between June 2018 and October 2020, we used a 4-step modified Delphi method (online survey, face-to-face nominal group technique $[n=12]$, semistructured telephone interview $[n=8]$ and nominal group technique $[n=12]$ ) to achieve national consensus from an expert panel of all 17 heads of academic divisions of general surgery in Canada on the roles and accompanying tasks essential to education, research and leadership services within an academic division of general surgery. We used $70 \%$ agreement to determine consensus.

Results: The expert panel agreed that a framework for role allocation in education, research and leadership services was relevant and necessary. Consensus was reached for 7 roles within the educational service, 3 roles within the research service and 5 roles within the leadership service.

Conclusion: Our framework represents a national consensus that defines role standards for education, research and leadership services in Canadian academic divisions of general surgery. The framework can help divisions build resiliency, and enable sustained and deliberate advances in these services.

Contexe : Il est nécessaire d'opérer une transition vers un modèle de financement standard, similaire à celui qui est appliqué aux services cliniques, pour les rôles essentiels au fonctionnement des services d'éducation, de recherche et de leadership à l'intérieur des divisions de chirurgie générale afin de rendre ces dernières plus résilientes. Nous avons voulu identifier les rôles et les tâches afférentes à ces services indispensables au fonctionnement durable des divisions de chirurgie générale dans les facultés de médecine canadienne.

Méthodes : Entre juin 2018 et octobre 2020, nous avons utilisé une méthode Delphi modifiée en 4 étapes (sondage en ligne, technique de groupe nominal en personne $[n=12]$, entrevue téléphonique semi-structurée $[n=8]$ technique de groupe nominal $[n=12]$ ) pour obtenir le consensus national d'un comité d'experts formé des 17 chefs de division de chirurgie générale au Canada au sujet des rôles et diverses tâches afférentes aux services dévolus à l'enseignement, à la recherche et au leadership dans les divisions de chirurgie générale. Nous avons utilisé un seuil d'assentiment de $70 \%$ pour déterminer le consensus.

Résultats : Le comité d'experts a convenu qu'il était pertinent et nécessaire d'établir un cadre d'attribution des rôles en éducation, recherche et leadership. Un consensus a été atteint pour 7 rôles du segment éducation, 3 rôles du segment recherche et 5 rôles du segment leadership.

Conclusion : Notre cadre représente un consensus national et définit les normes applicables aux rôles essentiels aux services en éducation, en recherche et en leadership dans les divisions de chirurgie générale au Canada. Ce cadre peut rendre les divisions plus résilientes, et favoriser leur développement de manière soutenue et délibérée. 
A cademic divisions of general surgery in Canada are defined by 3 mandates that are core to their mission statements: 1) delivering excellent clinical care, 2) maintaining an accredited training program that graduates competent surgeons and 3) creating a research infrastructure that fosters innovation. ${ }^{1}$ These services are intrinsically connected and interdependent. ${ }^{2-4}$ They are enabled by leadership that recognized not only the complexities of each domain, but also that an alignment must occur for the entire division to function (Figure 1). Many divisions of general surgery have mission statements documenting commitments to these domains. However, the existence of a mission statement without tangible support and resources for the key elements can risk authenticity and loss in engagement of members. ${ }^{5}$ Mission statements should guide the commitment to invest; resource efforts can convert an intended set of values into reality.

Academic physician remuneration in Canada is still mostly based on a clinical fee-for-service payment model. Whereas provincial standards provide funding and define performance metrics in clinical service, no such detailed guidance is defined for surgical education, research or leadership. ${ }^{6}$ The responsibility of allocating both human and financial resources for these services generally falls to the local surgical leadership. This can lead to variability in delivery of essential nonclinical services. ${ }^{6}$ As such, the divisional system that encompasses clinical and nonclinical services is unbalanced and may rely on surgeons' internal motivations to fulfill responsibilities for many nonclinical services. ${ }^{4,7}$

Leadership and governance is 1 of the 6 building blocks of a health care system as defined by the World Health Organization, which calls for attention to system design and accountability. ${ }^{8}$ From a systems management perspective, given the current way in which divisions are modelled and resourced (i.e., predominantly clinical fee-for-service), it is challenging to build a resilient, robust, stable division that enables deliberate advances in education, research or leadership without a framework that rewards these behaviours. A way to strengthen divisional resiliency is to move toward a common funding standard for nonclinical services. However, there is a lack of published information to help guide academic surgical leaders on how best to design a division in a way that formally support essential nonclinical services. The objective of this work was to identify and describe, through national consensus, the roles that are central to support the sustainable functioning of education, research and leadership services within Canadian academic general surgery divisions.

\section{Methods}

We used a 4-step modified Delphi method to gain national consensus on which roles and accompanying tasks are essential for the functioning of education, research and

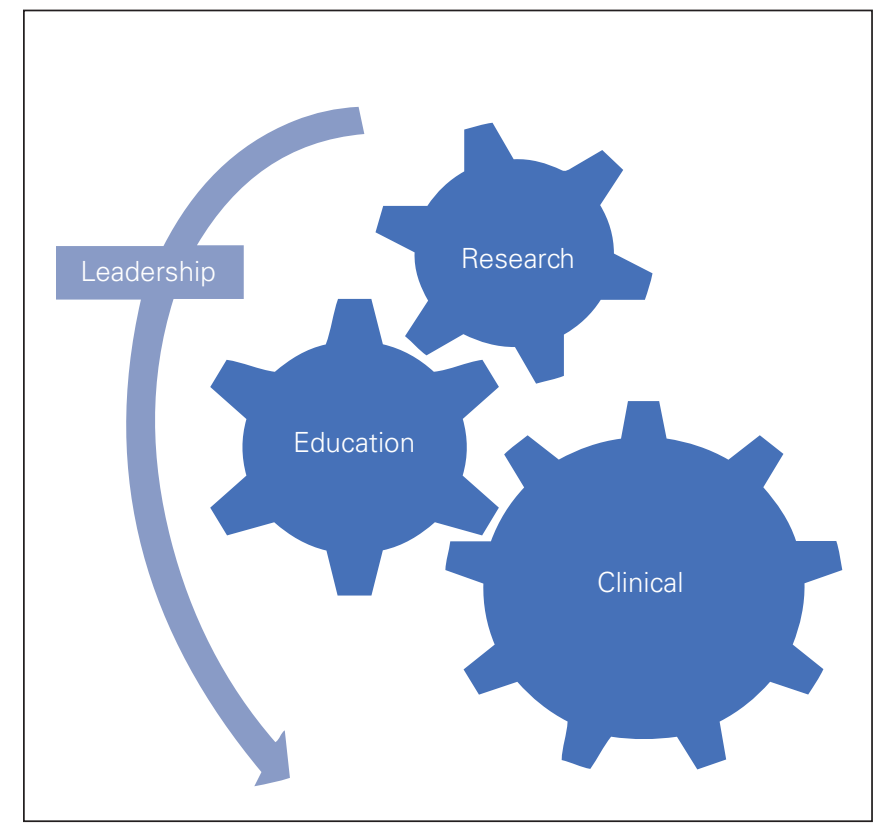

Fig. 1. Academic medical division system where clinical care is a combination of education and research enabled through leadership.

leadership services within Canadian academic general surgery divisions., ${ }^{9,10}$ This method is in accordance with the Canadian Fournal of Surgery consensus process. ${ }^{11}$

An expert panel including all 17 academic general surgery division heads in Canada was recruited through the Canadian Association of General Surgeons Division Chiefs Committee. The first round began in June 2018, when the expert panel members were asked to complete an online survey to gather information on demographic information and identify how nonclinical services (research, education and leadership) were defined and how roles were allocated across various Canadian academic or tertiary hospitals. The insight gained from the responses guided development of the subsequent phases.

In the second round, in September 2018, a panel of 12 of the 17 division heads met face to face in the style of a nominal group technique to discuss the results from the first round. At this time, it was thought that consensus would be achieved on suggested roles and tasks. However, it became apparent that there was substantial disagreement about the definition of nonclinical services, the terminology used to describe services and roles, and how services and roles could be measured. We thus instead sought and obtained validation that the topic area and study were relevant and required further investigation.

In the third round, in April 2019, semistructured telephone interviews were conducted by the first author with 8 division heads from the expert panel to reconcile discrepancies between the suggested roles and tasks, and gain a deeper understanding of the context that was driving these variations. An interview guide was developed 
based on roles that were discussed from the first and second rounds. Participants were asked whether such roles existed in their organization, to give a description of tasks, and whether there were other roles that should be included as essential. All interviews were recorded and transcribed verbatim by a transcription service. We used a conventional undirected content-analysis methodology adapted from Hsieh and Shannon ${ }^{12}$ for the qualitative analysis. As there is limited theory and literature on the management of academic divisions of general surgery, we coded for emerging themes using NVivo 12 software (QSR International) and ceased coding after reaching theoretical saturation. The codes and their descriptions were evaluated by 2 authors (M.R. and C.K.) between May and July 2019 to ensure that there was a coherent pattern and agreement in order to increase the confirmability of the findings.

The fourth round was in the style of a nominal group technique. A panel of 12 of the 17 division heads met face to face in September 2019 to discuss the results from the third round and obtain consensus for the developed framework. ${ }^{13}$ Panel members voted on their agreement to include each role and accompanying tasks as required for the functioning of essential nonclinical services. We used $70 \%$ agreement to determine consensus on the acceptance or rejection of a role and accompanying tasks. ${ }^{14}$ For education services, voting occurred by means of a show of hands, and anonymity was not retained. ${ }^{10}$ Panel members were encouraged to discuss the roles until agreement was reached to retain, modify or eliminate the role and accompanying tasks from the final framework. ${ }^{10}$ The panel was asked to provide their vote via email for the remaining research and leadership services by November 2019. We summarized each agreed-upon role and provided a description of how the roles and tasks are organized within each service. An initial draft and then a final iteration of the research findings were circulated among the expert panel members for confirmation.

This study was approved by the Ottawa Health Science Network Research Ethics Board (protocol ID 20180925$01 \mathrm{H}$ and 20180926-01H).

\section{Results}

The principal investigator leading the study and administering the online survey (F.B.) did not complete the survey. Of the remaining 16 division heads, 10 (62\%) completed the survey. The division heads reported an average of 27 surgeons, 28 residents and 4 fellows. On average, 3 hospitals were affiliated with each division.

The survey showed that most surgeons have additional responsibilities beyond clinical care. These nonclinical responsibilities include education, research and leadership. These responsibilities were defined as follows for the remainder of the study:
- Education is the delivery and uptake of surgical competencies;

- Research is knowledge generation and discovery;

- Leadership is the governance and enabling of people and processes.

The average proportion of divisional funds allocated collectively to education, research and leadership activities was $16.3 \%$. The division heads stated that increasing this amount was either impossible (5 respondents) or would take substantial effort (5 respondents) with their current funding approach.

The expert panel agreed that a framework for role allocation in education, research and leadership services was relevant and necessary.

\section{Roles and key tasks}

The roles and accompanying tasks agreed on through the consensus process were classified according to the 3 nonclinical responsibilities. A role was defined by a set of responsibilities, and tasks were the actions required to fulfill those responsibilities. Although one organization may select a certain position or title to refer to a role, and another organization may choose a different position or title to refer to the same role, the use of common terminology is central to the identification and classification of roles. The tasks associated with each role were classified as micro-level (requiring individual interaction), meso-level (requiring group interactions) or macro-level (requiring institutional interactions). There was recognition that certain roles do not exist in isolation and that there is a need to balance them, depending on organization constraints. For example, smaller divisions or divisions that operate with multiple hospital sites may be unable to delineate specific roles simply because they do not have enough staff.

\section{Leadership}

The various leadership roles and tasks encompassed a broad range of responsibilities (Table 1). The tasks of the division head reached beyond representing the division to include individual coaching, mentorship and career development. Consensus was achieved around defining other key leadership roles spanning finance, supervision of clinical programs and quality improvement. Responsibilities of the divisional director of finance included leading the acquisition and distribution of funding within the division. The section head role included tasks related to coordination of clinical programs, interfacing with hospital and cross-organizational administration, directing specialtyspecific rounds, and incorporating provincial standards to patient care. Quality assurance of division-wide activities was assigned to the quality assurance/improvement lead, and the site chief was responsible for site-specific issues including scheduling and resource allocation. 
Table 1 (part 1 of 2). Roles and key tasks for leadership services in an academic division of general surgery

\begin{tabular}{|c|c|}
\hline Role; level & Key tasks \\
\hline Division head & - Provide overarching divisional leadership and direction \\
\hline Macro* & $\begin{array}{l}\text { - Be the face of the division: do activities that reflect the } \\
\text { strength of the university nationally and internationally; } \\
\text { do activities that are in the best interest of the division } \\
\text { - Contribute to fundraising activities } \\
\text { - Create a positive culture } \\
\text { - Facilitate efforts to enhance/evolve the division } \\
\text { - Liaise with hospital regarding union rules and issues } \\
\text { - Recruit faculty } \\
\text { - Represent the division at external meetings }\end{array}$ \\
\hline Meso* & $\begin{array}{l}\text { - Allocate resources or assign a designate (e.g., clinic } \\
\text { time, operating room schedule, on-call schedules, } \\
\text { outpatient resources) } \\
\text { - Chair/coordinate/attend internal executive and } \\
\text { operational meetings } \\
\text { - Complete annual reporting requirements } \\
\text { - Coordinate functioning of the division (maintain a broad } \\
\text { overview of research and education activities within } \\
\text { the division) } \\
\text { - Deal with division-wide clinical service delivery issues } \\
\text { - Ensure adequate administrative support } \\
\text { - Ensure that quality-based metrics, volumes and targets } \\
\text { are met (quality assurance/improvement) } \\
\text { - Oversee budget assigned from hospital to services } \\
\text { - Provide updates on provincial changes in policy }\end{array}$ \\
\hline Micro* & $\begin{array}{l}\text { - Adjudicate clinical and behavioural issues } \\
\text { (e.g., disciplinary matters) } \\
\text { - Appoint surgeons into nonclinical roles } \\
\text { - Coach and assign mentors for junior surgeons } \\
\text { - Deal with complaints } \\
\text { - Facilitate/support surgeons' academic careers } \\
\text { (e.g., promotions, learning environment, Grand } \\
\text { Rounds, annual update, other continuing medical } \\
\text { education activity) } \\
\text { - Lead/participate in faculty evaluation for hospital and } \\
\text { university reappointment } \\
\text { - Organize or delegate division Grand Rounds }\end{array}$ \\
\hline $\begin{array}{l}\text { Divisional } \\
\text { director of } \\
\text { finance }\end{array}$ & $\begin{array}{l}\text { - Oversee budgeting for all divisional activities } \\
\text { - Division may have representation only at the } \\
\text { departmental level }\end{array}$ \\
\hline Meso & $\begin{array}{l}\text { - Allocate budget to each nonclinical pillar, including } \\
\text { research, education and leadership } \\
\text { - Fundraise for various initiatives } \\
\text { - Consult on personnel and equipment negotiations } \\
\text { relevant to the division } \\
\text { - Present budget to and seek budget approval from } \\
\text { division members/divisional executive }\end{array}$ \\
\hline Micro & $\begin{array}{l}\text { - Supervise accounts } \\
\text { - Prepare yearly accounting reports } \\
\text { - Authorize disbursements }\end{array}$ \\
\hline Section head & $\begin{array}{l}\text { - Responsible for clinical functioning and coordination of } \\
\text { a sectiont }\end{array}$ \\
\hline Micro & - Deal with offences and complaints \\
\hline Meso & $\begin{array}{l}\text { - Coordinate clinical functioning and appropriate resource } \\
\text { allocation of the section } \\
\text { - Lead program-specific committee } \\
\text { - Liaise with hospital or cross-organizational } \\
\text { administration } \\
\text { - Lead quality assurance/improvement responsibilities } \\
\text { (e.g., meeting provincial standards for wait times, } \\
\text { review and respond to disease site NSQIP data) } \\
\text { - Lead specialty-specific rounds (e.g., tumour board) }\end{array}$ \\
\hline
\end{tabular}

Table 1 (part 2 of 2). Roles and key tasks for leadership services in an academic division of general surgery

\begin{tabular}{ll}
\hline Role; level & \multicolumn{1}{c}{ Key tasks } \\
\hline Site chief & $\begin{array}{l}\text { Extension of division head responsibilities dealing } \\
\text { primarily with scheduling }\end{array}$ \\
\hline Meso & Represent division head at departmental/hospital \\
& committees (e.g., hospital perioperative services \\
& committee, department of surgery executive \\
& committee) as needed \\
& - Manage site-specific issues including scheduling \\
& (operating room and on-call) and resource allocation \\
Quality & Oversee adherence to relevant quality standards and \\
assurance/ & develop quality-improvement initiatives \\
improvement & \\
lead & Develop division-wide quality-improvement \\
\hline Meso & activities \\
& Represent division at departmental/hospital quality \\
& assurance/improvement committee \\
& Monitor and report morbidity and mortality \\
& within division \\
& Represent/lead division in \\
& quality initiatives
\end{tabular}

NSQIP = American College of Surgeons National Surgical Quality Improvement Program. *These tasks describe the mandate for both the academic (university) and clinical

(hospital) organization. If these roles are not occupied by the same person, there would

be a need to clarify the allocation of responsibilities.

tSections refer to a subspecialty and could also be referred to as clinical services, units or programs. Examples include colorectal surgery, foregut/bariatric, general surgical oncology, breast surgical oncology and hepatobiliary surgery.

\section{Education}

Roles in education spanned the entire continuum of support for learners at the undergraduate level to the fellowship training level (Table 2). With regard to postgraduate training, roles to support the program director may include an assistant program director in larger programs and a Competence by Design lead. The surgeons fulfilling these roles may maintain communication with trainees, provide quality assurance and lead critical elements of the program such as chairing a competence committee. Supervision of day-to-day delivery of training was allotted to the section coordinator, who is responsible for defining learning objectives and providing summative evaluations.

\section{Research}

Last, the expert panel identified surgeon researcher roles (Table 3). Tasks for surgeon-scientists included leading an established research program, whereas surgeoninvestigators are responsible for leading or participating in research projects. Within any given academic division, there will be fewer surgeon-scientists than surgeoninvestigators, but the specific number will vary depending on the size and nature of the research. The task of advancing divisional research efforts was assigned to the divisional director of research, who provides individual mentorship, builds a divisional research strategy and aim, and creates opportunities for productivity and research dissemination. 
Table 2 (part 1 of 2). Roles and key tasks for education services in an academic division of general surgery

\begin{tabular}{|c|c|}
\hline vel & Key tasks \\
\hline $\begin{array}{l}\text { Program } \\
\text { director }\end{array}$ & $\begin{array}{l}\text { - Oversee residency program, Canadian Resident } \\
\text { Matching Service process, curriculum development, } \\
\text { assessment and promotion } \\
\text { - Maintain RCPSC accreditation } \\
\text { - Set tone for the culture of the training program }\end{array}$ \\
\hline Macro & - Secure/maintain RCPSC accreditation \\
\hline Meso & $\begin{array}{l}\text { - Chair residency program committee } \\
\text { - Coordinate all aspects of Canadian Resident Matching } \\
\text { Service process } \\
\text { - Develop curriculum/educational content } \\
\text { - Facilitate residency research curriculum } \\
\text { - Liaise between university and residents } \\
\text { - Liaise between residency program committee and } \\
\text { division } \\
\text { - Provide or delegate planning of academics } \\
\text { (e.g., specific teaching sessions) } \\
\text { - Set the culture of the program (e.g., help to } \\
\text { organize annual research day, social events, } \\
\text { graduation) }\end{array}$ \\
\hline Micro & $\begin{array}{l}\text { - Assign residents to clinical services/rotations, including } \\
\text { - } \text { Coneduling residents } \\
\text { and recomments residents to RCPSC to sit their } \\
\text { examinations } \\
\text { - Guide residents through study and preparation plan for } \\
\text { national examinations (e.g., Surgical Foundations } \\
\text { Examination) } \\
\text { - Promote or remediate residents following evaluations } \\
\text { - Provide mentorship and career advice } \\
\text { - Provide oversight of assessments/evaluation of } \\
\text { residents } \\
\text { - Provide oversight of resident clinical or nonclinical } \\
\text { leave (e.g., academic, vacation) in compliance with } \\
\text { union } \\
\text { - Supervise or work closely with Competence by } \\
\text { Design lead/Surgical Foundations Program director } \\
\text { - Support resident well-being (initial contact to residents } \\
\text { who are struggling personally or professionally) } \\
\text { - Work with section coordinator for resident education } \\
\text { on items related to education }\end{array}$ \\
\hline $\begin{array}{l}\text { Associate/ } \\
\text { assistant } \\
\text { program } \\
\text { director* }\end{array}$ & $\begin{array}{l}\text { - Support program director } \\
\text { - Be available to residents as an intermediate to help } \\
\text { with issues } \\
\text { - Be involved in succession planning for next program } \\
\text { director }\end{array}$ \\
\hline Meso & $\begin{array}{l}\text { - Substitute for program director when necessary } \\
\text { (e.g., when he or she is away) } \\
\text { - Support program director with any specific delegated } \\
\text { tasks }\end{array}$ \\
\hline Micro & $\begin{array}{l}\text { - Act as intermediary if a resident is } \\
\text { having issues } \\
\text { - Maintain regular communication with residents and } \\
\text { obtain ongoing feedback with regard to the quality of } \\
\text { the program }\end{array}$ \\
\hline $\begin{array}{l}\text { Competence } \\
\text { by Design } \\
\text { leadt }\end{array}$ & $\begin{array}{l}\text { - Implement delivery of Competence by Design and } \\
\text { resident evaluation system }\end{array}$ \\
\hline Meso & $\begin{array}{l}\text { - Chair/participate on competency committee } \\
\text { - Oversee implementation of } \\
\text { Competence by Design }\end{array}$ \\
\hline Micro & $\begin{array}{l}\text { - Evaluate residents on entrustable professional } \\
\text { activities } \\
\text { - Review resident evaluations and provide resident } \\
\text { status recommendations to program director }\end{array}$ \\
\hline
\end{tabular}

Table 2 (part 2 of 2). Roles and key tasks for education services in an academic division of general surgery

\begin{tabular}{|c|c|}
\hline Role; level & Key tasks \\
\hline $\begin{array}{l}\text { Section } \\
\text { coordinator for } \\
\text { resident } \\
\text { education } ¥\end{array}$ & $\begin{array}{l}\text { - Oversee expectations and evaluations of residents } \\
\text { within a section }\end{array}$ \\
\hline Meso & $\begin{array}{l}\text { - Define goals, objectives and expectations for residents } \\
\text { within a clinical rotation } \\
\text { - Represent section on residency training committee }\end{array}$ \\
\hline Micro & $\begin{array}{l}\text { - Act as contact for residents during rotation } \\
\text { - Assign residents to surgical staff } \\
\text { - Ensure timely evaluations } \\
\text { - Integrate residents into service schedule } \\
\text { (e.g., operating room, clinics) } \\
\text { - Provide feedback to residents } \\
\text { - Provide orientation to residents }\end{array}$ \\
\hline $\begin{array}{l}\text { Undergraduate } \\
\text { medical lead§ }\end{array}$ & $\begin{array}{l}\text { - Lead curriculum development and evaluations for } \\
\text { medical students }\end{array}$ \\
\hline Meso & $\begin{array}{l}\text { - Develop curriculum, including development of goals } \\
\text { and objectives for clerkship rotation } \\
\text { - Liaise with division/department to integrate surgical } \\
\text { component } \\
\text { - Sit on undergraduate medical } \\
\text { education committee }\end{array}$ \\
\hline Micro & $\begin{array}{l}\text { - Coordinate student evaluations/assessments } \\
\text { - Provide orientation for students }\end{array}$ \\
\hline $\begin{array}{l}\text { Fellowship } \\
\text { program } \\
\text { director(s) }\end{array}$ & $\begin{array}{l}\text { - Maintain accreditation and help foster career } \\
\text { development of fellows }\end{array}$ \\
\hline Macro & $\begin{array}{l}\text { - Secure/maintain accreditation of program } \\
\text { (e.g., RCPSC, Fellowship Council) }\end{array}$ \\
\hline Meso & $\begin{array}{l}\text { - Coordinate all aspects of fellowship selection process } \\
\text { - Coordinate education of fellows with education of } \\
\text { residents } \\
\text { - Develop curriculum/educational content } \\
\text { - Facilitate a fellowship research curriculum in the } \\
\text { program } \\
\text { - Liaise between university and fellows } \\
\text { - Liaise between residency program committee } \\
\text { and division } \\
\text { - Provide or delegate planning of academics } \\
\text { (e.g., specific teaching sessions) } \\
\text { - Set the culture of the program (e.g., help organize } \\
\text { annual research day, social events, graduation) }\end{array}$ \\
\hline Micro & $\begin{array}{l}\text { - Confirm fellows' successful completion of program } \\
\text { and eligibility for certification examinations (as } \\
\text { relevant) } \\
\text { - Promote or remediate fellows } \\
\text { following evaluations } \\
\text { - Provide mentorship and career advice to fellows } \\
\text { - Provide oversight of assessments/evaluation of } \\
\text { residents } \\
\text { - Provide oversight of fellows' clinical or nonclinical } \\
\text { leave (e.g., academic, vacation) in compliance with } \\
\text { union } \\
\text { - Support fellows' well-being (e.g., initial contact with } \\
\text { fellows who are struggling personally or professionally) } \\
\text { - Work with section resident rotation coordinator on } \\
\text { items related to education }\end{array}$ \\
\hline \multicolumn{2}{|c|}{$\begin{array}{l}\text { RCPSC = Royal College of Physicians and Surgeons of Canada. } \\
\text { *This role is greatly dependent on the size of program, value to residents and distribution } \\
\text { of learning. } \\
\text { †This role will continue to evolve as Competence by Design continues to be } \\
\text { implemented. } \\
\ddagger \text { Also known as clinical teaching unit director. } \\
\text { §ivision may have representation only at the departmental level. }\end{array}$} \\
\hline
\end{tabular}


Table 3. Roles and key tasks for research services in an academic division of general surgery

\begin{tabular}{|c|c|}
\hline Role; level & Key tasks \\
\hline $\begin{array}{l}\text { Divisional director } \\
\text { of research* }\end{array}$ & $\begin{array}{l}\text { - Support research direction, objectives and } \\
\text { activities } \\
\text { - May have some authority over a research budget }\end{array}$ \\
\hline Meso & $\begin{array}{l}\text { - Aid, as appropriate, in securing external funding } \\
\text { and support } \\
\text { - Define overall research strategy for the division, } \\
\text { including internal funding allocation for research } \\
\text { pillar } \\
\text { - Distribute awards, scholarships and grants through } \\
\text { departmental research committee } \\
\text { - Organize annual research day for the division } \\
\text { - Support publications and conference attendance } \\
\text { through departmental research committee }\end{array}$ \\
\hline Micro & $\begin{array}{l}\text { - Mentor/facilitate surgeons' (staff and residents) } \\
\text { research objectives } \\
\text { - Organize and host information and orientation } \\
\text { sessions for trainees and supervisors }\end{array}$ \\
\hline $\begin{array}{l}\text { Surgeon- } \\
\text { investigator }\end{array}$ & $\begin{array}{l}\text { - Divide time between clinical practice and } \\
\text { supporting research } \\
\text { - Appointment at university or research institute } \\
\text { - Not restricted to clinical research; could be } \\
\text { involved in educational research, for example }\end{array}$ \\
\hline Micro & $\begin{array}{l}\text { - Collaborate and be engaged in research teams } \\
\text { - Publish as a coinvestigator, collaborator or senior } \\
\text { author } \\
\text { - Carry out research in a defined area of focus } \\
\text { - Supervise fellows, residents and medical students } \\
\text { in research projects }\end{array}$ \\
\hline $\begin{array}{l}\text { Surgeon- } \\
\text { scientist† }\end{array}$ & $\begin{array}{l}\text { - Lead a research program while holding clinical } \\
\text { responsibilities } \\
\text { - Appointment at university or research institute } \\
\text { may be subject to reappointment review } \\
\text { - Cross-appointed at faculty of graduate and } \\
\text { postdoctoral studies }\end{array}$ \\
\hline Micro & $\begin{array}{l}\text { - Hold peer-reviewed or other grants as primary } \\
\text { investigator } \\
\text { - Lead a "program" of research } \\
\text { - Publish as primary investigator or senior author of } \\
\text { high-impact papers } \\
\text { - Supervise fellows, residents and graduate } \\
\text { students }\end{array}$ \\
\hline
\end{tabular}

\section{Funding arrangements}

Findings from the qualitative analysis showed that participants agreed that funding and funding arrangements are a core tenet related to the roles and tasks required for the 3 nonclinical essential services. There was concern that the breadth of selected roles and any accompanying "invisible" tasks may not be adequately factored into compensation. The following quotation from one of the semistructured interviews highlights the way in which an individual surgeon felt valued by their institution for nonclinical tasks and how that was affected by current funding models:

It's very blurred, and I get money from the university, and I get money from the hospital. And it's almost a token amount, but it's necessary for me because otherwise, if you don't get any money ... what's the value in it to the university? And what's the value to the hospital? Even if it's small. University hospital cut me last year, cut all of us because [of a] budget squeeze. And that was fine. I don't mind getting cut, but if you said it [the funding] was zero, I might have a problem with it, just because it means that the position isn't valued. (Division head ID1)

Further findings from the qualitative analysis showed that other roles in education, research or leadership may offer no funding, be less formalized or have vague performance metrics, yet people fulfill these tasks for a variety of reasons, including personal interest and professional development. As illustrated in the following quotation, more comprehensive funding arrangements that enable reduced clinical responsibilities in favour of contributions to education, research or leadership enable a shift to greater collective accountability:

Asking someone to do something in our centre at the expense of reduced clinical activity usually doesn't hit the wall as quickly as it might for surgeons who are predominantly funded [via a] feefor-service arrangement. I think we have a little bit more latitude that way to assign tasks that are, obviously, going to take away from clinical productivity. Collectively we have to meet an accountability framework. Collectively we have to deliver on the clinical side. Individuals have a little more flexibility. (Division head ID5)

\section{Discussion}

To our knowledge, this paper presents the first national consensus framework to guide service structure in Canadian academic divisions of general surgery while addressing the paucity of national standards on resourcing essential roles beyond clinical care. Efforts to support essential nonclinical services formally require a shift in mindset whereby the relations between domains are recognized and actions are taken to support division alignment. The modified Delphi process yielded a systems-based framework that can be used to guide development of a comprehensive and equitable division with sustainable capacity in academic services. There was universal receptivity to mapping the framework across the 3 pillars of education, research and leadership, and to defining the underlying tasks that fulfill these roles. Specific responsibilities under each academic role were stratified into micro-, meso- and macro-level tasks that align with system levels in health care, which each have specific goals, resources and processes that are characteristic to how they function. ${ }^{15,16}$ Key tasks under each role therefore provide a mechanism to ensure that improvements and solutions to academic services are developed with support from the appropriate people and resources, and are targeted at the appropriate level of the division. 
As the framework is grounded in systems management, divisions across Canada will be able to foster a common model of service structure that enhances authenticity to their mission statements, increases accountability and governance, and provides a guide for resource allocation and investment in these services. However, in adopting the selected roles and tasks, divisions need to take into consideration their local context to determine whether the roles and tasks are justified and feasible. Notably, some roles may depend on the size of the program or may share representation with the medical department or faculty. Moreover, the responsibilities under these roles are expected to evolve over time with advancements in curricula and research. The position of a Competence by Design lead, for example, must be adaptive to nation-wide transitions from an apprenticeship model to an outcomebased curriculum paradigm based on the evolving standards for resident training. ${ }^{17-19}$

Achieving concurrent success in all domains of clinical and nonclinical services with the use of this framework will require a shift from striving for individual success to aiming for collective success in the academic division by employing systems-based management. Systems-based management convenes a variety of formal approaches to frame complexities in health care management as interdependent components within the larger system entity. ${ }^{20-22}$

Although a shift away from focus on the individual surgeon may seem counterintuitive to enhancing provider experience, a governance system that is designed to enable collective identity and responsibility around education, research and leadership can enable a more positive provider experience. ${ }^{23}$ For example, clinicians could lead aspects of divisional responsibilities pertaining to their skill sets and career goals (e.g., interest in educational services) but hold more supportive roles and accountabilities with respect to other nonclinical services that are not their primary focus, all of which would contribute to collective divisional success. ${ }^{23}$ This could be achieved by designing a flexible division with dedicated funding for nonclinical roles and responsibilities. Such a strategy must ultimately embrace a more balanced funding model of fee-fordivisional service where divisional services include education, research and leadership, allowing divisions to better align themselves with their objectives in both clinical and nonclinical services. By linking these services, decisionmakers can maintain divisional resiliency when pressures threaten to disrupt an individual service (such as when the COVID-19 pandemic threatened funding of certain clinical services and altered funding of research areas). ${ }^{24}$ The local leadership will be in the best position to determine a suitable mechanism for implementing such a model. However, one possible mechanism is to have internal taxation or tithing system whereby a proportion of total divisional earnings are redistributed to fund the essential nonclinical services. Furthermore, a division could implement "day rates" whereby a surgeon would be compensated at a standard rate per hour or per day for completing tasks specific to an essential role in education, research or leadership.

Although the 17 Canadian academic divisions of general surgery exhibit considerable heterogeneity with respect to size, geographic location and funding models, consensus achieved in this study shows that these divisions share a similar mission with regard to the 3 pillars of nonclinical academic services. ${ }^{1}$ By identifying the roles needed to maintain and advance essential nonclinical services, the framework that we present can be used to deliver on a division's mission statement by recognizing the value of these services while providing a blueprint through which divisional leadership can guide strategies and investment when determining responsibilities and compensation. Nationally, this framework represents a common syntax around structuring academic services in general surgery, and fosters a platform for interdivisional learning and discussion of strategies that enhance the value of these roles. In turn, leaders can streamline workforce planning by better predicting which skills are needed for specific tasks and which skills may contribute to better retention through professional development opportunities and recruitment rates.

For the individual provider, a divisional structure that allocates resources and funding based on the presented framework can ultimately be used to improve surgeon morale and sense of belonging to the division. It is well understood that financial incentives do not fully explain why surgeons strive to provide excellent clinical care, research innovation and role model as teachers. ${ }^{7,25,26}$ Nonfinancial motivators and other prosocial behaviours (e.g., desire for personal growth, promotion and tenure, being part of a team) surely contribute. However, relying on a clinician's intrinsic motivation instead of designing a system to formally support the individual is a precarious way to create individual accountability and does not lend well to overall divisional accountability and success. Simultaneous mastery across the entire spectrum of clinical care, education, research and leadership is difficult to achieve when traditional service models (i.e., clinical feefor-service) do not protect time for these roles, the result of which has been heightened awareness in the literature on increasing clinical well-being and reducing burnout rates. ${ }^{27-30}$ The presented framework offers a guide on how divisions can invest resources in essential services beyond clinical care, thereby showing the value of a surgeon's contribution and, at the time same time, increasing divisional resiliency.

This study spanned several years and iterative steps, including semistructured interviews, to comprehensively achieve consensus among the expert panel. We defined roles and tasks while keeping in mind the variability that may exist depending on the local context of the division 
and the advances in surgical education and research. As such, this framework represents a national consensus that defines current standards and can also guide future advances in nonclinical service structure in general surgery. A natural extension of this framework includes assessing the time required by each role, which could provide a starting point for divisional investment.

\section{Limitations}

Although no data were collected from stakeholders other than division heads in academic divisions of general surgery, division heads are responsible for representing their respective divisions while understanding and overseeing the entire functioning of their clinical and nonclinical programs. This makes them appropriate participants for this study. However, more granularity would have been gained by engaging other roles in the expert panel, such as program director, director of finance or surgeonscientist.

\section{Conclusion}

We used a modified Delphi process to generate a national consensus framework to guide role allocation in education, research and leadership services in Canadian academic divisions of general surgery. Adopting and advancing a divisional system that enables collective identity and responsibility around these essential nonclinical services will require a mechanism for accountability and performance measurement. The set of tasks outlined for each role in this framework can help apply uniform rules and standards that can also be measured to assess performance as a mechanism for accountability. From a system management perspective, the resultant division will be more resilient to external pressures and better positioned to cultivate the skill sets of the workforce to authentically deliver on its mission statement pertaining to clinical care, education, research and leadership.

Acknowledgements: The authors thank Dawn Wilson for her help in coordinating the face-to-face meetings, and Dr. Caolan Walsh for his work in design of the survey.

Affiliations: From the Telfer School of Management, University of Ottawa, Ottawa, Ont. (Reid); the Division of General Surgery, Department of Surgery, Faculty of Medicine, University of Ottawa, Ottawa, Ont. (Lee, Pagliarello, Balaa); the Division of General Surgery, Department of Surgery, Schulich School of Medicine and Dentistry, Western University, London, Ont. (Leslie); the Department of Surgery, McGill University, Montréal, Que. (Feldman); the Department of Surgery, University of British Columbia, Vancouver, BC (Hameed); the Division of Clinical Sciences, Northern Ontario School of Medicine, Laurentian University, Sudbury, and Lakehead University, Thunder Bay, Ont. (Kirkpatrick); the Division of Surgery, McMaster University, Hamilton, Ont. (Lovrics); the Department of Surgery, Queen's University, Kingston, Ont. (MacDonald); the Department of Surgery, Memorial University of Newfoundland, St. John's, Nfld. (Pace, Mathieson); the College of Medicine, University of Saskatchewan, Saskatoon, Sask. (Shaw); the Department of Surgery, Mount
Sinai Hospital, University of Toronto, Toronto, Ont. (Swallow); the Department of Surgery, Faculty of Medicine and Dentistry, University of Alberta, Edmonton, Alta. (Bigam, Porter); the Division of General Surgery, Department of Surgery, Université de Sherbrooke, Sherbrooke, Que. (McFadden); the Division of General Surgery, Department of Surgery, Université de Montréal, Montréal, Que. (Lapointe); the Department of Surgery, Foothills Medical Centre, University of Calgary, Calgary, Alta. (MacLean); and the Office of Research Services and School of Business, MacEwan University, Edmonton, Alta. (Kuziemsky).

Competing interests: Tony MacLean reports an honorarium from Ethicon. No other competing interests were declared.

Contributors: M. Reid, L. Feldman, A. Mathieson, C. Kuziemsky and F. Balaa designed the study. M. Reid, K. Leslie, R. Kirkpatrick, H. MacDonald, D. Pace, J. Shaw, C. Swallow, G. Pagliarello, N. McFadden, T. MacLean, C. Kuziemsky, D. Bigam and G. Porter acquired the data, which M. Reid, A. Lee, L. Feldman, M. Hameed, P. Lovrics, H. MacDonald, J. Shaw, R. Lapointe, T. MacLean and F. Balaa analyzed. M. Reid, A. Lee and F. Balaa wrote the manuscript, which all authors critically revised. All authors gave final approval of the article to be published.

Content licence: This is an Open Access article distributed in accordance with the terms of the Creative Commons Attribution (CC BYNC-ND 4.0) licence, which permits use, distribution and reproduction in any medium, provided that the original publication is properly cited, the use is noncommercial (i.e., research or educational use), and no modifications or adaptations are made. See: https://creativecommons. org/licenses/by-nc-nd/4.0/.

Funding: This work was supported through the University of Ottawa Interdisciplinary Research Group Funding Opportunity.

\section{References}

1. About Canadian Association of General Surgeons. Canadian Association of General Surgeons. Available: https://cags-accg.ca/about/ (accessed 2020 July 13).

2. Hameed SM, Brenneman FD, Ball CG, et al. General surgery 2.0: the emergence of acute care surgery in Canada. Can 7 Surg 2010;53: 79-83.

3. Tran A, Gawad N, Martel A, et al. The changing face of academic general surgery in Canada: a cross-sectional cohort study. Can 7 Surg 2019;62:381-5.

4. Sener A, Anderson CC, Auger FA, et al. Best practices for enhancing surgical research: a perspective from the Canadian Association of Chairs of Surgical Research. Can 7 Surg 2019;62:488-98.

5. Desmidt S, Prinzie AA. The organization's mission statement: Give up hope or resuscitate? A search for evidence-based recommendations. Adv Health Care Manag 2011:10:25-41.

6. Physicians in Canada, 2018. Ottawa: Canadian Institute for Health Information; 2019.

7. Leitch KK, Walker PM. Surgeon compensation and motivation. Arch Surg 2000;135:708-12.

8. Everybody's business: strengthening bealth systems to improve health outcomes. WHO's framework for action. Geneva: World Health Organization; 2007.

9. Nair R, Aggarwal R, Khanna D. Methods of formal consensus in classification/diagnostic criteria and guideline development. Semin Arthritis Rheum 2011;41:95-105.

10. Eubank BH, Mohtadi NG, Lafave MR, et al. Using the modified Delphi method to establish clinical consensus for the diagnosis and treatment of patients with rotator cuff pathology. BMC Med Res Methodol 2016;16:56.

11. McAlister V. Consensus ad idem: a protocol for development of consensus statements [editorial]. Can F Surg 2013;56:365.

12. Hsieh HF, Shannon SE. Three approaches to qualitative content analysis. Qual Health Res 2005;15:1277-88. 
13. Waggoner J, Carline JD, Durning SJ. Is there a consensus on consensus methodology? Descriptions and recommendations for future consensus research. Acad Med 2016;91:663-8.

14. Rezaie A, Buresi M, Lembo A, et al. Hydrogen and methane-based breath testing in gastrointestinal disorders: the North American Consensus. Am 7 Gastroenterol 2017;112:775-84.

15. Incident Analysis Collaborating Parties. Canadian Incident Analysis Framework. Edmonton: Canadian Patient Safety Institute; 2012.

16. System factors. Canadian Patient Safety Institute. Available: https:// www.patientsafetyinstitute.ca/en/toolsResources/PatientSafetyIncident ManagementToolkit/SystemFactors/Pages/default.aspx (accessed 2020 June 24).

17. Hoffman RL, Morris JB, Kelz RR. Surgical residency training at a university-based academic medical center. Surg Clin N Am 2016;96: 59-70.

18. Martin RF. Alternative considerations for surgical training and funding. Surg Clin North Am 2016;96:35-46.

19. Competence by Design. Ottawa: Royal College of Physicians and Surgeons of Canada. Available: http://www.royalcollege.ca/rcsite/ cbd/competence-by-design-cbd-e (accessed 2020 July 13).

20. Kuziemsky C. A message from the guest editor [editorial]. Healthc Manage Forum 2019;32:118-9.

21. Peters DH. The application of systems thinking in health: Why use systems thinking? Health Res Policy Syst 2014;12:51.
22. Khan S, Vandermorris A, Shepherd J, et al. Embracing uncertainty, managing complexity: applying complexity thinking principles to transformation efforts in healthcare systems. BMC Health Serv Res 2018;18:192.

23. National Academies of Sciences, Engineering, and Medicine; National Academy of Medicine; Committee on Systems Approaches to Improve Patient Care by Supporting Clinician Well-Being. Taking action against clinician burnout. Washington: National Academies Press; 2019:37-56.

24. Jenei K, Cassidy-Matthews C, Virk P, et al. Challenges and opportunities for graduate students in public health during the COVID-19 pandemic. Can 7 Public Health 2020;111:408-9.

25. Berdud M, Cabasés JM, Nieto J. Incentives and intrinsic motivation in healthcare. Gac Sanit 2016;30:408-14.

26. Judson TJ, Volpp KG, Detsky AS. Harnessing the right combination of extrinsic and intrinsic motivation to change physician behavior. 7AMA 2015;314:2233-4.

27. Awasthi S, Beardmore J, Clark J, et al. The future of academic medicine: five scenarios to 2025. New York: Milbank Memorial Fund; 2005:2-7.

28. Fischer JE. The impending disappearance of the general surgeon. 7AMA 2007;298:2191-3.

29. Stein SL. Scholarship in academic surgery: history, challenges, and ideas for the future. Clin Colon Rectal Surg 2013;26:207-11.

30. Bodenheimer T, Sinsky C. From triple to quadruple aim: care of the patient. Ann Fam Med 2014;12:573-6. 